\title{
SINTOMAS VISUAIS DE DEFICIÊNCIAS DE MICRONUTRIENTES E COMPOSIÇÃO MINERAL DE FOLHAS EM MUDAS DE GOIABEIRA ${ }^{1}$
}

\author{
JOÃO ODEMIR SALVADOR ${ }^{2}$, ADÔNIS MOREIRA ${ }^{3}$ e TAKASHI MURAOKA ${ }^{4}$
}

\begin{abstract}
RESUMO - Com o objetivo de verificar os sintomas visuais de deficiência nutricional de micronutrientes e avaliar a composição mineral das folhas, conduziu-se um experimento em solução nutritiva. Os tratamentos foram assim constituídos: (1) solução completa (testemunha); (2) menos B; (3) menos Cu; (4) menos Fe; (5) menos Mn; (6) menos Mo; e (7) menos $\mathrm{Zn}$. As soluções foram renovadas a cada 20 dias. As deficiências de boro, cobre, ferro, manganês e zinco resultaram na manifestação de sintomas visíveis e característicos. Esse fato não foi verificado com relação ao Mo. As concentrações de cada nutriente no terceiro par de folhas dos tratamentos deficientes e completo, em $\mathrm{mg} \mathrm{kg}^{-1}$, foram respectivamente: B (7 e 43); $\mathrm{Cu}(2$ e 6); Fe (55 e 117); $\mathrm{Mn}$ (5 e 23) e $\mathrm{Zn}$ (9 e 14). Foram verificadas algumas interações, como, $\mathrm{Cu}$ x Fe, Cu x Mn, Fe x B, Fe x Zn, Mn x Zn, B x Ca e B x P. A quantidade de matéria seca produzida apresentou redução em todos os tratamentos em que a solução nutritiva era omissa em um micronutriente, exceto naquele em que o Mo estava ausente.
\end{abstract}

Termos para indexação: solução nutritiva, deficiência nutricional, sintomas de deficiência, Psidium guajava.

\section{VISUAL SYMPTOMS OF MICRONUTRIENT DEFICIENCY AND OF MINERAL CONTENT IN GUAVA YOUNG PLANT LEAVES}

\begin{abstract}
In order to identify the visual symptoms of micronutrient deficiency and of mineral content in the guava young plant leaves, seedlings were grown in a greenhouse experiment in seven different treatments as follows: (1) complete; (2) without B; (3) without Co; (4) without Fe; (5) without Mn; (6) without Mo; and (7) without $\mathrm{Zn}$. The solutions were changed every 20 days. All symptoms were described and the deficiencies due of boron, copper, iron, manganese and zinc could be clearly noticed in the leaves. This fact was not observed for Mo. After 65 days, the third pair of leaves was collected, to assess the nutrient contents which were in $\mathrm{mg} \mathrm{kg}^{-1}: \mathrm{B}(7-43) ; \mathrm{Cu}(2$ - 6); $\mathrm{Fe}(55-117)$; $\mathrm{Mn}(5$ - 23) e $\mathrm{Zn}(9$ - 14). The first number in parentheses represents the deficient treatment, and the second the complete treatment. Several interactions were found, such as $\mathrm{Cu}$ with $\mathrm{Fe}, \mathrm{Cu}$ with $\mathrm{Mn}, \mathrm{Fe}$ with B, Fe with Zn, Mn with Zn, B with Ca and B with P. A decrease on dry matter yield could be observed when certain micronutrients were not applied, except for the one in which Mo was absent.

Index terms: nutrient solution, nutritional deficiency, deficiency symptoms, Psidium guajava.
\end{abstract}

\section{INTRODUÇÃO}

Os investimentos aplicados em cultivos de goiabeira para produção comercial em alta escala apre-

\footnotetext{
${ }^{1}$ Aceito para publicação em 4 de novembro de 1998.

${ }^{2}$ Biólogo, Laboratório de Fertilidade do Solo, Centro de Energia Nuclear na Agricultura (CENA), USP, Caixa Postal 96, CEP 13400-970 Piracicaba, SP. E-mail: salvador@cena.usp.br

${ }^{3}$ Eng. Agr., M.Sc., Doutorando, Laboratório de Nutrição Mineral de Plantas, CENA-USP. Bolsista da FAPESP. E-mail: amoreira@pira.cena.usp.br

${ }^{4}$ Eng. Agr., Dr., Laboratório de Fertilidade do Solo, CENA-USP. Bolsista do CNPq.
}

sentam-se em expansão. $\mathrm{O}$ fruto, pelas amplas possibilidades de consumo nos mercados interno e externo, engaja a cultura em importantes projetos comerciais de irrigação nas regiões semi-áridas do Nordeste brasileiro, constituindo-se numa ótima opção para a diversificação da fruticultura regional (Gonzaga Neto \& Soares, 1995). O Estado de São Paulo apresenta 3.200 ha ocupados com o cultivo da goiabeira e responde por praticamente a metade da área plantada no país (Natale et al., 1994), e duas novas variedades - Rica e Paluma -, introduzidas por Pereira et al. (1982), com sugestivas características agronômicas, ocupam 30\% dessa área. 
A introdução de variedades com bom potencial produtivo, porém mais exigentes em nutrientes, deverá requerer maior atenção no acompanhamento técnico do estado nutricional dos pomares. Assim, serão necessárias observações detalhadas de todas as anormalidades visíveis apresentadas pelas plantas, numa tentativa de levá-las a interagir com outros parâmetros importantes de avaliação nutricional, como a diagnose foliar e a análise do solo.

Embora a possibilidade de ocorrer carência de um micronutriente seja menor do que a de um macronutriente (Raij, 1991), é necessário aprofundar os conhecimentos sobre as reais necessidade da goiabeira em micronutrientes, uma vez que, segundo Malavolta (1986), uma planta cultivada em solo pobre desses minerais pode apresentar diminuição no seu crescimento, com queda de $20 \%$ a $30 \%$ de sua produção.

No estudo de nutrição mineral de plantas é necessário considerar os nutrientes como um todo, porque, no processo de absorção, um pode exercer influência sobre o outro, dadas as possíveis interações que podem ocorrer, alterando, desta maneira, a composição mineral das folhas (Raij, 1991).

Com base no exposto, desenvolveu-se o presente estudo, com o objetivo de verificar os sintomas típicos e individualizados de deficiência nutricional de micronutrientes e, ao mesmo tempo, avaliar os efeitos dessas deficiências na composição mineral das folhas de goiabeira, mediante análise de macronutrientes e micronutrientes.

\section{MATERIAL E MÉTODOS}

O experimento foi conduzido no segundo semestre de 1996, em casa de vegetação do Centro de Energia Nuclear na Agricultura (CENA), USP, localizado no município de Piracicaba, SP, situado nas coordenadas $22^{\circ} 42^{\prime} 30^{\prime \prime}$ de LS e $47^{\circ} 38^{\prime} 0^{\prime \prime}$ de LW.

As plantas com $15 \mathrm{~cm}$ de altura, propagadas via sementes, obtidas de uma planta nativa e produtiva, foram transferidas para recipientes de plástico contendo dois litros de solução nutritiva completa, partindo da solução de Sarruge (1975), modificada para o referido experimento, quanto às fontes de $\mathrm{N}$ (Tabela 1) e ajustada para as seguintes concentrações de nutrientes, em mg L-1: 91 de N nítrico; 21 de $\mathrm{N}$ amoniacal; 15,5 de P; 97,5 de K; 60 de
Ca; 24 de Mg; 32 de S na forma de sulfato; 0,25 de B; 0,01 de $\mathrm{Cu} ; 2,5$ de Fe; 0,25 de Mn; 0,025 de Zn e 0,005 de Mo. As plantas foram conduzidas em haste única (ramo ortotrópico) até $50 \mathrm{~cm}$ de altura, e então foi eliminada a gema terminal, deixando-se, a partir de $20 \mathrm{~cm}$, três ou quatro ramos plagiotrópicos, bem distribuídos, de acordo com a recomendação de Gonzaga Neto \& Soares (1995), no processo de formação de copa. Esse procedimento visou possibilitar a avaliação média de nutrientes de três ou quatro pares de folhas/planta, conforme Natale et al. (1996), para diagnose de plantas em produção. Emitidas as brotações, as plantas foram submetidas, durante 75 dias, aos tratamentos, constituídos pelas soluções, diferenciadas da inicial apenas pela omissão de um micronutriente de cada vez (Tabela 1), perfazendo sete tratamentos, assim constituídos: solução completa (testemunha); solução nutritiva sem boro (-B); solução nutritiva sem cobre (-Cu); solução nutritiva sem ferro (-Fe); solução nutritiva sem manganês (-Mn); solução nutritiva sem molibdênio (-Mo) e solução nutritiva sem zinco (-Zn). O delineamento experimental foi inteiramente casualizado, com três repetições, e a unidade experimental constituiu-se de uma planta. As soluções foram preparadas com reagentes p.a. diluídos em água resultante da desionização de água destilada, trocadas em intervalo de 20 dias e constantemente arejadas. Diariamente, o volume das soluções foi verificado, e, quando necessário, completado com água desionizada. $\mathrm{O}$ pH da solução foi ajustado para $5 \pm 2$ somente no momento da troca.

Decidiu-se por avaliar somente os tratamentos que apresentaram sintomas visíveis de deficiência. Após 65 dias, foram coletadas, de cada tratamento, amostras de folhas compostas pertencentes ao terceiro par, contadas a partir do ápice, para a análise dos teores de macronutrientes e micronutrientes. Colheram-se, também, duas plantas de cada tratamento, que foram separadas em raiz, caule e folhas, para a determinação da matéria seca, em gramas, produzida pelos diferentes órgãos do vegetal, efeito relativo do elemento omitido na produção total de matéria seca, e relação parte aérea/raiz (PA/R). $\mathrm{O}$ tratamento sem Mo (-Mo) não foi avaliado, por não apresentar qualquer anormalidade, cujas possíveis causas da não-resposta são discutidas, em parte, com embasamento nos teores do nutriente obtidos nas sementes e nas folhas das plantas, mantidas em solução completa, antes da formalização dos tratamentos. O efeito relativo foi avaliado pelo método de porcentagem de suficiência ou produção relativa (Raij, 1991), adaptada para determinação do "crescimento relativo" (CR), através da fórmula:

$\mathrm{CR}=\frac{\text { Tratamento com o nutriente omitido }}{\text { Tratamento completo }} \times 100$. 
As folhas coletadas foram lavadas em água corrente e, posteriormente, enxaguadas em água destilada, submetidas à secagem em estufa de aeração forçada, com temperatura mantida entre $60^{\circ} \mathrm{Ce} 70^{\circ} \mathrm{C}$, pesadas, moídas em moinho tipo Wiley, e digeridas para a obtenção dos extratos. Os teores de $\mathrm{P}$ foram determinados pelo método da colorimetria do metavanadato, e os de K, por fotometria de chama; os de $\mathrm{Ca}, \mathrm{Mg}, \mathrm{Cu}, \mathrm{Fe}, \mathrm{Mn}$ e $\mathrm{Zn}$, por espectrometria de absorção atômica; os de $\mathrm{S}$, por turbidimetria do $\mathrm{Ba}_{2} \mathrm{SO}_{4} \mathrm{O} \mathrm{N}$ foi determinado pelo método semimicro Kjeldahl; o B por colorimetria de azometina $\mathrm{H}$; e o Mo pela colorimetria do tiocianato (Malavolta et al., 1997).

A produção de matéria seca e as concentrações de nutrientes foram analisadas estatisticamente e comparadas pelo teste de Tukey a $5 \%$ de probabilidade, de acordo com a metodologia descrita por Pimentel-Gomes (1990).

\section{RESULTADOS E DISCUSSÃO}

\section{Alterações morfológicas decorrentes da falta de micronutrientes}

As plantas submetidas aos tratamentos com omissão de micronutrientes na solução nutritiva apresentaram sinais de deficiência nas folhas quando o nível exigido para o crescimento vegetal foi abaixo do considerado suficiente. Os teores foliares verificados na Tabela 2 demonstram o efeito da omissão, revelando que a ausência de um elemento sempre resultou na redução de sua concentração na folha.

\section{Deficiência de boro}

Os efeitos da ausência do nutriente começaram a ser mais bem visualizados aos 35 dias após o início do tratamento. As folhas mais novas e mais estreitas do que as consideradas normais apresentaram leve clorose internerval, evoluindo do centro para os bordos da folha. Em seqüência, essas folhas tornaram-se pálidas, exibindo, posteriormente, um reticulado escuro das nervuras, que se destacavam sobre um fundo levemente clorótico. Essas folhas se encurvaram e se retorceram para baixo, como se o pecíolo tivesse sido quebrado, ocorrendo, em seguida, uma acentuada queda dos primeiros pares, mas persistindo as folhas mais velhas. Em estádio posterior, a carência determinou a morte dos pontos vegetativos, e, em parte, secamento dos ramos, de maneira descendente (dieback). Isso propiciou, subseqüentemente, a emissão de novos ramos, próximos à região basal. As plantas deficientes em B apresentaram folhas menores, de textura pergaminhosa e mais espessa em relação à das fo-

TABELA 1. Composição $\left(\mathrm{mL} \mathrm{L}^{-1}\right)$ das soluções nutritivas completa (testemunha) e com omissão de micronutrientes (-B, -Cu, -Fe, -Mn, -Mo e - Zn) a que foram submetidas as goiabeiras.

\begin{tabular}{lccccccc}
\hline Substância & Testemunha & $-\mathrm{B}$ & $-\mathrm{Cu}$ & $-\mathrm{Fe}$ & $-\mathrm{Mn}$ & $-\mathrm{Mo}$ & $-\mathrm{Zn}$ \\
\hline $\mathrm{KH}_{2} \mathrm{PO}_{4} 1 \mathrm{~mol} \mathrm{~L}^{-1}$ & 0,5 & 0,5 & 0,5 & 0,5 & 0,5 & 0,5 & 0,5 \\
$\mathrm{KNO}_{3} 1 \mathrm{~mol} \mathrm{~L}^{-1}$ & 1,5 & 1,5 & 1,5 & 1,5 & 1,5 & 1,5 & 1,5 \\
$\mathrm{Ca}\left(\mathrm{NO}_{3}\right)_{2} 1 \mathrm{~mol} \mathrm{~L}^{-1}$ & 1,5 & 1,5 & 1,5 & 1,5 & 1,5 & 1,5 & 1,5 \\
$\mathrm{MgSO}_{4} 1 \mathrm{~mol} \mathrm{~L}^{-1}$ & 1,0 & 1,0 & 1,0 & 1,0 & 1,0 & 1,0 & 1,0 \\
$\mathrm{NaNO}_{3} 1 \mathrm{~mol} \mathrm{~L}^{-1}$ & 0,5 & 0,5 & 0,5 & 0,5 & 0,5 & 0,5 & 0,5 \\
$\mathrm{NH}_{4} \mathrm{NO}_{3} 1 \mathrm{~mol} \mathrm{~L}^{-1}$ & 1,5 & 1,5 & 1,5 & 1,5 & 1,5 & 1,5 & 1,5 \\
$\mathrm{KCl} 1 \mathrm{~mol} \mathrm{~L}^{-1}$ & 0,5 & 0,5 & 0,5 & 0,5 & 0,5 & 0,5 & 0,5 \\
Micronutrientes & 0,5 & - & - & - & - & - & - \\
Micronutrientes - B & - & 0,5 & - & - & - & - & - \\
Micronutrientes - Cu & - & - & 0,5 & - & - & - & - \\
Micronutrientes - Fe & - & - & - & 0,5 & - & - & - \\
Micronutrientes - Mn & - & - & - & - & 0,5 & - & - \\
Micronutrientes - Mo & - & - & - & - & - & 0,5 & - \\
Micronutrientes - Zn & - & - & - & - & - & - & 0,5 \\
Fe - EDTA & 0,5 & 0,5 & 0,5 & - & 0,5 & 0,5 & 0,5 \\
\hline
\end{tabular}

${ }^{1}$ Solução estoque: $2,86 \mathrm{~g} \mathrm{~L}^{-1} \mathrm{de} \mathrm{H}_{3} \mathrm{BO}_{3} ; 1,81 \mathrm{~g} \mathrm{~L}^{-1}$ de $\mathrm{MnCl}_{2} \cdot 4 \mathrm{H}_{2} \mathrm{O} ; 0,22 \mathrm{~g} \mathrm{~L}^{-1}$ de $\mathrm{ZnSO}_{4} \cdot 7 \mathrm{H}_{2} \mathrm{O} ; 0,08 \mathrm{~g} \mathrm{~L}^{-1}$ de $\mathrm{CuSO}_{4} \cdot 5 \mathrm{H}_{2} \mathrm{O} ; 0,02 \mathrm{~g} \mathrm{~L}^{-1} \mathrm{de}$ $\mathrm{H}_{2} \mathrm{MoO}_{4} \cdot \mathrm{H}_{2} \mathrm{O}$. 
lhas normais. Foi observado, ainda, ao longo da nervura central e em pontos do caule, a formação de algumas protuberâncias, de origem corticosa. Quanto ao caule, na região do colo surgiram fendas ou fissuras longitudinais. Quanto ao sistema radicular, observaram-se raízes um pouco mais grossas e com as radicelas apresentando tênues lesões necróticas escurecidas, principalmente nas extremidades.

A imobilidade do B no floema implica necessidade contínua de suprimento do nutriente durante todo o período vegetativo da planta (Hu \& Brown, 1997; Malavolta et al., 1997). De acordo com Malavolta (1980), a deficiência de B, juntamente com a de $\mathrm{Zn}$, tanto em culturas anuais como em perenes, é das mais comuns no Brasil. Segundo o autor, a pobreza do solo em matéria orgânica ou em B total, a falta de umidade, com inibição do processo de mineralização da matéria orgânica, e a calagem excessiva, são fatores que podem favorecer a manifestação dos sintomas da falta do nutriente.

Deficiência de cobre

Aos 20 dias após o início do tratamento, foram observados os primeiros sintomas da deficiência do elemento. As plantas deficientes em $\mathrm{Cu}$, inicialmente, apresentaram áreas cloróticas e esparsas nas folhas mais novas. A seguir, à medida que a deficiência se agravou, os limbos foliares mostraram uma superfície enrugada ou deformada, com saliências ou proeminências das nervuras secundárias, formando as chamadas "costelas". A morte precoce das gemas terminais forçou a emissão de gemas vegetativas axilares múltiplas, originando brotações com folhas diminutas, mais arredondadas e com crestamento na ponta. $\mathrm{O}$ desenvolvimento apical desses lançamentos foram de duração efêmera. Outro tipo de manifestação foliar, decorrente da falta do nutriente, consistiu na formação e irradiação de uma mancha clorótica através das nervuras central e secundárias, em direção aos pontos periféricos da folha. Em condições de extrema carência, as folhas mais velhas apresentaram aspecto normal, porém mais escuras quando comparadas às do tratamento completo. Algumas folhas da região mediana mostraram um amarelecimento, formando uma extensa mancha clorótica, que dividiu o limbo em dois tons distintos: verde-escuro e verde-pálido.

De maneira geral, a elevação do $\mathrm{pH}$ do solo, o elevado teor de matéria orgânica e o excesso de N, $\mathrm{P}$ e Zn, favorecem o aparecimento da deficiência de $\mathrm{Cu}$ (Malavolta, 1980; Mengel \& Kirkby, 1987; Marschner, 1995).

TABELA 2. Matéria seca produzida de caule, folha, raiz e total ( $\mathrm{g}$ planta $\left.{ }^{-1}\right)$ da goiabeira, crescimento relativo (CR) e relação parte aérea/raiz (PA/R) aos 65 dias depois da aplicação dos diferentes tratamentos. Média de duas repetições ${ }^{1}$.

\begin{tabular}{lcccccc}
\hline Tratamento & Caule & Folha & Raiz & Total & CR & PA/R \\
\hline Testemunha & $22,25 \mathrm{a}$ & $23,66 \mathrm{a}$ & $16,46 \mathrm{a}$ & $62,37 \mathrm{a}$ & 100 & 2,79 \\
-B & $9,27 \mathrm{~cd}$ & $11,40 \mathrm{bc}$ & $8,99 \mathrm{~b}$ & $29,66 \mathrm{~cd}$ & 47 & 2,30 \\
$-\mathrm{Cu}$ & $9,23 \mathrm{~cd}$ & $8,43 \mathrm{c}$ & $8,92 \mathrm{~b}$ & $26,58 \mathrm{~cd}$ & 43 & 1,98 \\
-Fe & $7,09 \mathrm{~d}$ & $8,22 \mathrm{c}$ & $7,38 \mathrm{~b}$ & $22,69 \mathrm{~d}$ & 36 & 2,07 \\
-Mn & $15,03 \mathrm{~b}$ & $18,72 \mathrm{ab}$ & $8,80 \mathrm{~b}$ & $42,55 \mathrm{~b}$ & 68 & 3,83 \\
-Zn & $14,31 \mathrm{bc}$ & $10,91 \mathrm{bc}$ & $11,57 \mathrm{~b}$ & $36,79 \mathrm{bc}$ & 59 & 2,18 \\
\hline D.M.S. & 5,47 & 8,10 & 4,88 & 12,33 & & \\
C.V. $(\%)$ & 15,51 & 21,80 & 17,10 & 12,23 & & \\
\hline
\end{tabular}

${ }^{1}$ Médias seguidas pela mesma letra na vertical não diferem significativamente a $5 \%$ de probabilidade pelo teste de Tukey. 


\section{Deficiência de ferro}

A falta do elemento causou a alteração na coloração das folhas novas, que apresentaram nervuras bem pronunciadas, na tonalidade verde, formando um nítido contraste com o resto amarelado do limbo. Com a severidade da deficiência e queda dos níveis de clorofila, as folhas tornaram-se totalmente cloróticas, e, mais tarde, esbranquiçadas, caracterizando um tênue atraso em seu crescimento e no da planta. As folhas inferiores e/ou medianas apresentaram cor e tamanho normais. O sistema radicular mostrou-se com tonalidade marrom ou ferruginosa, e a ausência de raízes secundárias resultou em um sistema radicular curto, grosso e quebradiço.

Segundo Malavolta (1980), Mengel \& Kirkby (1987) e Marschner (1995) a elevação do pH, o excesso de matéria orgânica, as elevadas concentrações de $\mathrm{P}, \mathrm{Cu}, \mathrm{Mn}$ e $\mathrm{Zn}$ e o encharcamento do solo são fatores que induzem à carência de Fe.

\section{Deficiência de manganês}

O sintoma de deficiência do nutriente, na fase inicial, é brando e visualizado nas folhas mais sombreadas e opacas do terço médio do ramo principal e dos plagiotrópicos, que aduzem uma leve clorose internerval, contrastando com o verde das nervuras e adjacências. Essa clorose é mais perceptível quando se observa o dorso da folha contra a luz. Áreas verde-azuladas, distribuídas irregularmente pelo limbo, também podem ocorrer. As folhas mais jovens, no início da deficiência, apresentaram-se com esparsas áreas cloróticas adjacentes à nervura principal. As folhas em formação, devido à pigmentação natural existente, apresentaram nervuras bem verdes, formando um nítido contraste com o resto avermelhado do limbo. No ramo principal, as folhas apresentaram certa torção, com curvatura para baixo, enquanto nos demais ramos dispuseram-se em ângulo mais agudo em relação à haste. Deve ser registrado, ainda, que as plantas carentes em $\mathrm{Mn}$ apresentaram, durante um determinado período, desenvolvimento aparentemente normal, com as folhas atingindo dimensões até mesmo maiores, porém mais opacas. Todavia, com o progredir da carência, a planta entrou em estado de debilidade recrudescente, ocorrendo a emissão de folhas me- nores, mais claras e com uma enfática clorose malhada nos lançamentos novos.

A elevação do $\mathrm{pH}$, os teores elevados de matéria orgânica (Raij, 1991) e as altas concentrações de $\mathrm{P}, \mathrm{Cu}$ e $\mathrm{Zn}$ (Malavolta, 1980) reduzem a disponibilidade do manganês para as plantas.

Deficiência de molibdênio

Não foi verificado indício de deficiência do elemento, provavelmente em decorrência do curto período do experimento; da reserva adquirida na fase de preparo das mudas; da quantidade existente na semente; ou, ainda, em decorrência da contaminação dos sais utilizados. Para Tiffin (1972), as quantidades de Mo encontradas nas sementes são, geralmente, suficientes para que as plantas se desenvolvam ou então adiem os sintomas de deficiência. Deve ser registrado que a semente de goiaba continha $0,29 \mathrm{mg} \mathrm{kg}^{-1}$ de Mo. Segundo Johnson (1966), as plantas apenas mostram sinais de deficiência de Mo quando seus teores, são menores que $0,1 \mathrm{mg} \mathrm{kg}^{-1}$ na matéria seca da parte aérea. O teor do nutriente encontrado no terceiro par de folhas das plantas mantidas em solução completa antes de serem submetidas ao tratamento em solução nutritiva omissa em Mo foi de $0,25 \mathrm{mg} \mathrm{kg}^{-1}$, concentração que pode ter sido suficiente para não produzir os efeitos esperados.

\section{Deficiência de zinco}

As manifestações morfológicas decorrentes da carência de $\mathrm{Zn}$ se estabeleceram 30 dias a partir do início do tratamento e foram mais pronunciadas nas folhas mais jovens. Essas folhas apresentaram-se pequenas, mais estreitas e pontiagudas, com nervuras salientes e encurvamento da lâmina para cima e, às vezes, para baixo ao longo da nervura principal, com as margens voltadas para a face central; mostraram, também, uma forte clorose internerval com as nervuras bem realçadas de verde e manchas ou pequenas pontuações castanhas distribuídas pelo limbo. Ocorreu formação de ramos finos e atrofiamento vegetativo, gerando uma planta anã e descaracterizada.

A adubação elevada com $P$ e o nível elevado do $\mathrm{pH}$ do solo podem induzir deficiências de $\mathrm{Zn}$ (Malavolta, 1980; Mengel \& Kirkby, 1987; Raij, 1991; Marschner, 1995). Pelas descrições, as ma- 
nifestações de carência de B, $\mathrm{Cu}, \mathrm{Fe}, \mathrm{Mn}$ e $\mathrm{Zn}$, estabeleceram-se, mais visivelmente, no terço superior das plantas, justificando as afirmações de Dell et al. (1995), Marschner (1995) e Malavolta et al. (1997), sobre a baixa redistribuição desses nutrientes.

\section{Produção de matéria seca (MS)}

Os dados de produção de matéria seca de caule, folha e raiz, da relação parte aérea/raiz e do índice de "crescimento relativo", de plantas submetidas aos diferentes tratamentos, são apresentados na Tabela 2. A deficiência de B, Cu, Fe, Mn e Zn levou ao decréscimo da produção de MS. Os índices obtidos no que diz respeito à produção total de MS de caule, folha e raiz da Tabela 2 mostram que a produção relativa obedeceu à seguinte ordem decrescente: Testemunha $>-\mathrm{Mn}>-\mathrm{Zn}>-\mathrm{B}>-\mathrm{Cu}>-\mathrm{Fe}$, deduzindo-se, dessa maneira, que o desenvolvimento da planta, durante o período experimental, foi menos afetado pela carência de $\mathrm{Mn}$, com redução de $32 \%$ da MS e mais afetado pelo $\mathrm{Fe}$, com redução de $64 \%$ da MS. Os resultados também evidenciam que a carência de Mn apresentou a relação parte aérea/raiz com maior quociente e, portanto, em termos percentuais, menor quantidade de matéria seca das raízes $(28 \%)$. Nos demais tratamentos, esses índices se mantêm bem próximos. Quociente menor, neste caso, pode estar relacionado com a redução da área foliar, que afeta o numerador. Em todos os tratamentos, exceto no $-\mathrm{Zn}$, o peso da matéria seca total das folhas foi semelhante ao do caule.

\section{Composição de micronutrientes}

Os efeitos da carência individual de cada micronutriente sobre os teores de $\mathrm{B}, \mathrm{Cu}, \mathrm{Fe}, \mathrm{Mn}$ e Zn, são apresentados na Tabela 3. Nessa tabela, o menor valor estabelecido para cada coluna referese ao teor do nutriente omitido. Observa-se que a carência de $\mathrm{B}$ não afetou a absorção dos nutrientes catiônicos, porém, sua absorção foi maior nas ausências de $\mathrm{Cu}$ e $\mathrm{Fe}$. A deficiência de $\mathrm{Cu}$, além de proporcionar aumento no teor de B, elevou, também, o de Mn e o de Fe, apesar de o teor desse último não ter apresentado diferença significativa em relação ao da testemunha, possivelmente em decor- rência do alto coeficiente da variação. Maiores concentrações de $\mathrm{B}, \mathrm{Cu}$ e $\mathrm{Zn}$ são verificadas no tratamento em que o Fe foi suprimido. Entre Mn e Zn ocorreu efeito de inibição; a ausência de um aumentou a concentração do outro. Exceto com relação ao $\mathrm{B}$, as alterações observadas para $\mathrm{Cu}, \mathrm{Fe}, \mathrm{Mn}$ e Zn ajustam-se às afirmações de Loué (1993), de que por serem cátions bivalentes, existe uma competição dos nutrientes pelo mesmo sítio de absorção, de maneira que a carência de um aumenta a disponibilidade do outro.

\section{Composição de macronutrientes}

Os efeitos da ausência individual de cada micronutriente sobre os teores de N, P, K, Ca e Mg, determinados nos tecidos da terceira folha, são mostrados na Tabela 4. Verifica-se que a falta de B acarretou diminuição nos teores de $\mathrm{Ca}$ e $\mathrm{P}$. A redução do teor de Ca pode ser resultante do efeito de uma menor taxa de transpiração que ocorre quando há deficiência do nutriente, como relatam Baker et al. (1956), uma vez que o Ca é dependente do fluxo transpiratório para ascender às partes mais novas (Isermann, 1970). Para Marschner (1995), a sustentabilidade da existência da interação Ca x B deve estar alicerçada no fato de ambos exercerem uma função estrutural das membranas e parede ce-

TABELA 3. Concentração de micronutrientes $\left(\mathrm{mg} \mathrm{kg}^{-1}\right)$ no $3^{\circ}$ par de folhas de goiabeira, coletadas aos 65 dias depois da aplicação dos diferentes tratamentos. Média de três repetições ${ }^{1}$.

\begin{tabular}{lrcccc}
\hline Tratamento & $\mathrm{B}$ & $\mathrm{Cu}$ & $\mathrm{Fe}$ & $\mathrm{Mn}$ & $\mathrm{Zn}$ \\
\hline Testemunha & $43 \mathrm{~b}$ & $6 \mathrm{~b}$ & $117 \mathrm{ab}$ & $23 \mathrm{bc}$ & $14 \mathrm{~b}$ \\
$-\mathrm{B}$ & $7 \mathrm{c}$ & $4 \mathrm{bc}$ & $87 \mathrm{~b}$ & $43 \mathrm{~b}$ & $13 \mathrm{bc}$ \\
$-\mathrm{Cu}$ & $67 \mathrm{a}$ & $2 \mathrm{c}$ & $203 \mathrm{a}$ & $87 \mathrm{a}$ & $14 \mathrm{bc}$ \\
$-\mathrm{Fe}$ & $64 \mathrm{a}$ & $8 \mathrm{a}$ & $55 \mathrm{~b}$ & $34 \mathrm{~b}$ & $22 \mathrm{a}$ \\
$-\mathrm{Mn}$ & $47 \mathrm{~b}$ & $4 \mathrm{bc}$ & $81 \mathrm{~b}$ & $5 \mathrm{c}$ & $21 \mathrm{a}$ \\
- Zn & $46 \mathrm{~b}$ & $5 \mathrm{~b}$ & $120 \mathrm{ab}$ & $72 \mathrm{a}$ & $9 \mathrm{c}$ \\
\hline D.M.S. & 8,21 & 2,14 & 114,22 & 28,41 & 5,29 \\
C.V. $(\%)$ & 13,47 & 16,75 & 38,35 & 23,52 & 12,63 \\
\hline
\end{tabular}

${ }^{1}$ Médias seguidas pela mesma letra na vertical não diferem significativamente a $5 \%$ de probabilidade pelo teste de Tukey. 
TABELA 4. Concentração de macronutrientes $\left(\mathrm{g} \mathrm{kg}^{-1}\right)$ no $3^{\circ}$ par de folhas de goiabeira, coletadas aos 65 dias depois da aplicação dos diferentes tratamentos. Média de três repetições ${ }^{1}$.

\begin{tabular}{lllllll}
\hline Tratamento & $\mathrm{N}$ & $\mathrm{P}$ & $\mathrm{K}$ & $\mathrm{Ca}$ & $\mathrm{Mg}$ & $\mathrm{S}$ \\
\hline Testemunha & $24,70 \mathrm{c}$ & $2,23 \mathrm{ab}$ & $16,57 \mathrm{~b}$ & $9,57 \mathrm{ab}$ & $3,97 \mathrm{a}$ & $2,17 \mathrm{~b}$ \\
$-\mathrm{B}$ & $20,80 \mathrm{c}$ & $1,67 \mathrm{~b}$ & $19,00 \mathrm{~b}$ & $5,17 \mathrm{c}$ & $3,33 \mathrm{a}$ & $2,10 \mathrm{~b}$ \\
$-\mathrm{Cu}$ & $26,80 \mathrm{bc}$ & $2,23 \mathrm{ab}$ & $22,90 \mathrm{ab}$ & $11,40 \mathrm{a}$ & $5,10 \mathrm{a}$ & $2,20 \mathrm{~b}$ \\
$-\mathrm{Fe}$ & $25,63 \mathrm{bc}$ & $2,17 \mathrm{ab}$ & $23,90 \mathrm{ab}$ & $7,00 \mathrm{bc}$ & $3,83 \mathrm{a}$ & $4,47 \mathrm{a}$ \\
-Mn & $36,70 \mathrm{a}$ & $2,77 \mathrm{a}$ & $32,67 \mathrm{a}$ & $7,37 \mathrm{bc}$ & $3,90 \mathrm{a}$ & $2,97 \mathrm{ab}$ \\
-Zn & $32,80 \mathrm{ab}$ & $2,83 \mathrm{a}$ & $24,40 \mathrm{ab}$ & $8,13 \mathrm{abc}$ & $5,37 \mathrm{a}$ & $3,07 \mathrm{ab}$ \\
\hline D.M.S. & 7,46 & 0,92 & 10,58 & 3,37 & 2,13 & 1,71 \\
C.V. $(\%)$ & 9,75 & 14,42 & 16,70 & 15,18 & 18,26 & 22,10 \\
\hline
\end{tabular}

${ }^{1}$ Médias seguidas pela mesma letra na vertical não diferem significativamente a $5 \%$ de probabilidade pelo teste de Tukey.

lular. No entanto, Gupta (1979) considera os relatos da literatura sobre as relações dos teores de $\mathrm{Ca}$ e B inconclusivos. O B é um nutriente que também influencia a atividade de componentes específicos de membranas celulares, que são importantes no transporte de P. Em caso de deficiência de B, há diminuição da atividade da ATPase, reduzindo a disponibilidade de energia para a absorção iônica ativa e passagem de açúcares-P e aminoácidos (Malavolta et al., 1997).

À medida que as folhas crescem, há uma diluição, diminuindo a concentração de nutrientes. Com base nesse princípio, acredita-se que o acréscimo na concentração de $\mathrm{N}$, decorrente da carência de $\mathrm{Zn}$, esteja relacionado com esse efeito, porque as folhas das plantas testemunhas foram bem maiores em relação às das desenvolvidas sob carência de $\mathrm{Zn}$. Determinando-se o acúmulo de $\mathrm{N}$ e relacionando-se o peso da matéria seca total das folhas dos tratamentos testemunha e - $\mathrm{Zn}$ (Tabela 2) com os respectivos teores obtidos na folha-padrão (Tabela 4), obtêm-se valores de $0,58 \mathrm{~g}$ de $\mathrm{N}$ na testemunha e $0,36 \mathrm{~g}$ no tratamento $-\mathrm{Zn}$.

O Mn é um dos constituintes da redutase do nitrito (Malavolta et al., 1997), de maneira que a atividade da enzima é prejudicada quando ocorre a carência do nutriente. Um acúmulo de $\mathrm{N}$ na forma não protéica nas folhas, dada a baixa atividade da redutase do nitrato, pode ser um dos motivos do aumento no teor de $\mathrm{N}$ no tratamento -Mn. O outro, é que a redução da atividade enzimática tenha, pos- sivelmente, proporcionado maior absorção de $\mathrm{N}$ na forma amoniacal.

Para Olsen (1972), as interações de micronutrientes com macronutrientes constituem um fato marcante, e ajudam a identificar as razões de casos não esclarecidos apenas pela avaliação dos teores individuais dos nutrientes (Raij, 1991). Algumas das interações, como Zn x N, Zn x P e B x Ca, observadas no presente trabalho (Tabela 4), são mencionadas por Raij (1991).

\section{CONCLUSÕES}

1. A falta de B, Cu, Fe, Mn e Zn na solução nutritiva resulta em alterações morfológicas, traduzidas como sintomas característicos de deficiência nutricional de cada nutriente.

2. O Mn é o micronutriente que menos afeta a fase inicial do desenvolvimento da goiabeira.

3. As deficiências individuais de micronutrientes promovem alterações na composição mineral de macronutrientes e micronutrientes.

4. Há efeito de inibição entre $\mathrm{Cu}$ e $\mathrm{Fe}$ e $\mathrm{Mn}$ e Zn nas mudas de goiabeira.

\section{REFERÊNCIAS}

BAKER, J.E.; GAUCH, H.G.; DUGGER JÚNIOR, W.M. Effect of boron on the water relations of higher plants. Plant Physiology, Rockville, v.31, n.1, p.89-94, 1956. 
DELL, B.; MALAJCZUK, N.; GROVE, T.S. Nutrient disorders in plantation of eucalyptus. Camberra: ACIAR, 1995. 104p.

GONZAGA NETO, J.; SOARES, J.M. A cultura da goabeira. Brasília: EMBRAPA-SPI, 1995. 75p.

GUPTA, U.C. Boron nutrition of crops, Advances in Agronomy, New York, v.31, p.273-307, 1979.

HU, H.; BROWN, P.H. Absorption of boron by plants roots. In: DELL, B.; BROWN, P.H.; BELL, R.W. (Eds.). Boron in soils and plants: Reviews. Dordrecht: Klumer Academic, 1997. p.49-58.

JOHNSON, C.M. Molybdenum. In: CHAPMAN, H.D. (Ed.). Diagnostic criteria for plants and soils. Berkeley: Univ. of California, 1966. p.286-301.

ISERMANN, K. The effects of adsorption process in the xylem on the calcium distribution in higher plants. Zeitschrift Pflanzernährung, Bodenkunde, v.26, n.1, p.191-203, 1970.

LOUÉ, A. Oligoeléments en Agriculture. Antibes: SCPA/NATHAN, 1993. 557p.

MALAVOLTA, E. Elementos de nutrição mineral de plantas. São Paulo: Agronômica Ceres, 1980.251p.

MALAVOLTA, E. Micronutrientes na adubação. Paulínia: Nutriplant, 1986. 70p.

MALAVOLTA, E.; VITTI, G.C.; OLIVEIRA, S.A. Avaliação do estado nutricional das planta; princípios e aplicações. Piracicaba: POTAFOS, 1997.319p.

MARSCHNER, H. Mineral nutrition of higher plants. London: Academic, 1995. 889p.
MENGEL, K.; KIRKBY, E.A. Principles of plant nutrition. Bern: International Potash Institute, 1987. $685 \mathrm{p}$.

NATALE, W.; COUTINHO, E.L.M.; BOARETTO, A.E.; CORTEZ, G.E.P.; FESTUCCIA, A.J. Extração de nutrientes por frutos de goiabeira (Psidium guajava L.). Científica, São Paulo, v.22, n.2, p.249-253, 1994.

NATALE, W.; COUTINHO, E.L.M.; BOARETTO, A.E.; PEREIRA, F.M. Goiabeira: calagem e adubação. Jaboticabal: FUNEP, 1996. 22p.

OLSEN, S.R. Micronutrients interactions. In: MORTVEDT, J.J.; GIORDANO, P.M.; LINDSAY, W.L. (Eds.). Micronutrients in Agriculture. Madison: Soil Science Society of America, 1972. p.243-264.

PEREIRA, F.M.; FERRATO, B.J.P.; KRONKA, S.N. Comportamento, em seleção preliminar, de nove cultivares de goiabeira (Psidium guajava L.) na região de Jaboticabal. Proceedings of the Tropical Region American Society for Horticultural Science, v.25, p.253-258, 1982.

PIMENTEL-GOMES, F. Curso de Estatística Experimental. Piracicaba: Nobel, 1990. 468p.

RAIJ, B. van. Fertilidade do solo e adubação. Piracicaba: Agronômica Ceres/POTAFOS, 1991.343p.

SARRUGE, J.R. Soluções nutritivas. Summa Phytopathologia, Piracicaba, v.1, n.3, p.231-233, 1975.

TIFFIN, L.O. Translocation of micronutrients in plants. In: MORTVEDT, J.J.; GIORDANO, P.M.; LINDSAY, W.L. (Eds.). Micronutrients in Agriculture. Madison: Soil Science Society of America, 1972. p.199-230. 